\title{
CIDADES ACESSÍVEIS: PANORAMA DA LEGISLAÇÃO NACIONAL E NORTE AMERICANA EM RELAÇÃO ÀS CATEGORIAS DE ACESSIBILIDADE.
}

\author{
OLIVEIRA, Natalia Consoli Marangoni de (1); \\ BERNARDI, Núbia (2) \\ (1) Universidade Estadual de Campinas, Formada no Programa de Formação Interdisciplinar \\ Superior - ProFIS ${ }^{1}$ \\ e-mail:n184875@g.unicamp.br \\ (2) Universidade Estadual de Campinas, Faculdade de Engenharia Civil, Arquitetura e \\ Urbanismo, Professora Doutora \\ e-mail: nubiab@fec.unicamp.br
}

\begin{abstract}
RESUMO
Esse artigo é resultante de uma revisão de literatura na qual foi realizada a contextualização histórica da legislação brasileira e legislação norte americana referente aos Direitos da Pessoa com Deficiência, principalmente no tocante às conceituações de acessibilidade e Desenho Universal. As legislações foram comparadas e classificadas conforme categorias de acessibilidade. Os resultados mostram algumas lacunas na implementação de medidas previstas em lei nos níveis regionais, estaduais elou municipais e apontam diretrizes a serem trabalhadas para a efetivação de algumas ações, principalmente no que se refere a Acessibilidade Arquitetônica.
\end{abstract}

Palavras chave: acessibilidade; Desenho Universal; legislação.

\begin{abstract}
This article is resultant of a literature review in which was made a historical contextualization of the Brazilian and the North American legislation on the Rights of Persons with Disabilities, especially as regard the concepts about accessibility and Universal Design. The legislations were compared and classified according to accessibility categories. The results show some gaps in the laws implementation at the regional, state and/or municipal levels, and suggest guidelines for effective actions, especially in regard to Architectural Accessibility.
\end{abstract}

Keywords: accessibility; Universal Design; legislation.

\section{INTRODUÇÃO}

Nas sociedades contemporâneas, o debate sobre acessibilidade se faz frequente e tem recebido cada vez maior importância social. Os desafios que enfrentam os arquitetos,

\footnotetext{
${ }^{1}$ O ProFIS é um curso superior de complementação de estudos, que possibilita uma formação geral, de caráter multidisciplinar. Ao concluir o curso, o aluno do ProFIS tem acesso a uma vaga em um dos cursos de graduação da UNICAMP, sem a necessidade de aprovação no vestibular. Fonte: Cursos de Graduação Unicamp. Disponível em https://www.dac.unicamp.br/sistemas/catalogos/grad/catalogo2017/cursos/cur200.html. Acesso em 2018.
} 


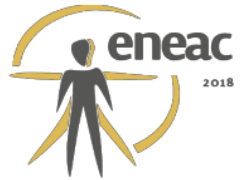

engenheiros, projetistas e legisladores se encontram na tarefa de idealizar e construir cidades que sejam de fato acessíveis a qualquer pessoa. Desde que se iniciou a concepção da ideia de dignidade humana e cidadania e, posteriormente, o longo percurso que levou até a Declaração dos Direitos Humanos em 1948, já se fazia ali também uma parte do conceito de acessibilidade que não considera pura e simplesmente o acesso, mas sim a pessoa humana e todo o ambiente e contexto nos quais ela se insere, assim como as relações estabelecidas entre ambos. Mais tarde, entre os anos 80 e 90, Ronald Mace defenderia os Sete Princípios do Desenho Universal, que visam uma arquitetura não excludente e apoiada sobre as determinações presentes nos Direitos Humanos (ADAPTIVE ENVIRONMENT, 2017).

No Brasil, o período de 2004 à 2015 foi marcado por duas revisões da norma que estabelece parâmetros de acessibilidade em construções, mobiliários, espaços e equipamentos urbanos, a NBR9050, e também pela divulgação de vasta legislação a respeito da promoção de acessibilidade, caracterizando-o como momento de grandes avanços na temática.

Este trabalho, através de uma revisão de literatura, objetivou a análise do foco dessas medidas, a partir da caracterização das mesmas nas categorias de acessibilidade defendidas por Romeu Sassaki (2004), e posterior discussão, entre a legislação nacional e norte americana, sobre sua efetividade em prol de uma acessibilidade universal.

\section{METODOLOGIA}

A metodologia adotada incidiu basicamente no estudo da literatura já existente referente ao tema, com foco na definição dos conceitos de acessibilidade e dos Princípios do Desenho Universal, que estivessem alinhados com o objetivo da pesquisa, e na legislação nacional e internacional estipuladas elou promulgadas durante o período de 2004 a 2015.

Como recorte do cenário internacional, foi escolhido o documento Americans with Disability Act (ADA) dos Estados Unidos, pois a legislação norte americana tem destaque entre diversos autores e foi uma base para a legislação brasileira. A legislação nacional utilizada é destacada pela Secretaria Nacional de Promoção dos Direitos da Pessoa com Deficiência SNPDP e pelo Conselho Nacional dos Direitos da Pessoa com Deficiência - CONADE (CONADE, 2017).

A análise da legislação brasileira foi feita com base em seis das sete categorias de acessibilidade descritas por Romeu Sassaki (2004). As categorias selecionadas são: arquitetônica, comunicacional, metodológica, instrumental, programática, atitudinal.

Houve a preocupação em elaborar o material digital do relatório, em especial a Tabela de Categorização, seguindo recomendações gráficas para leitura por pessoas com baixa visão. Desta forma os contrastes cromáticos e a disposição dos elementos foram diagramados para uma melhor visualização e compreensão do trabalho por este perfil de leitor (KULPA; TEIXEIRA; SILVA, 2010).

\section{LEVANTAMENTO BIBLIOGRÁFICO}

\section{1. Estado da Arte}

No decorrer da História a ideia de dignidade humana é gestada e discutida a partir de três principais pontos de vista: o religioso, baseado no Gênesis bíblico, o filosófico, atestado pelo grego Ésquilo e o científico, justificado pela teoria de Charles Darwin. Este último, descreve 


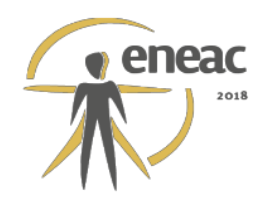

o homem como "capaz de agir sobre o mundo físico" e de "hominizar" a natureza, o que justificaria a "soberania" e dignidade humana (COMPARATO, 2010).

Tendo-a em vista, o homem passa a refletir sobre a pessoa humana e seus direitos "Foi durante o período axial da História, como se acaba de assinalar, que despontou a ideia de uma igualdade essencial entre todos os homens. Mas foram necessários vinte e cinco séculos para que a primeira organização internacional a englobar a quase totalidade de povos da Terra proclamasse, na abertura de uma Declaração Universal dos Direitos Humanos, que 'todos os homens nascem livres e iguais em dignidade e direitos." (COMPARATO, 2010).

Essa organização, por sua vez, tem também sua própria história, e dava seus primeiros sinais já no século XVIII, com a Revolução Americana (1775-1783). A Revolução Francesa de 1789, também tem sua participação no processo, movida pelos ideais de Liberdade, Igualdade e Fraternidade que embasaram a mudança na forma de pensar política. A Declaração dos Direitos do Homem e do Cidadão, de 26 de agosto de 1789, demonstra os súditos tornando-se cidadãos e tendo sua óptica da história considerada. Este documento foi a afirmação da conquista dessa revolução e inspiração para outras futuras declarações, dentre elas a dos Direitos Humanos (LAFER, 1995).

No século XIX, a criação da Cruz Vermelha em 1863 e a Primeira Convenção de Genebra em 1864 foram outras duas importantes afirmações históricas dos Direitos Humanos (LAFER, 1995). Entretanto, foi o final da II Guerra Mundial, em 1945, que deu a esses sinais um caminho definido e impulso. Esse foi um período de profunda reflexão para toda a sociedade global. As atrocidades cometidas durante essa guerra e justificadas por ela tomaram proporções que o homem moderno desconhecia até então. A preocupação com a chamada "paz entre as nações" motivou a criação da Carta da ONU.

Essa carta opunha-se ao paradigma hobbesiano-maquiavélico de que a lei que rege o sistema internacional é a Lei da Sobrevivência. Continha traços grocianos sobre as potenciais solidariedade e sociabilidade entre as nações, um "interesse recíproco do estado". Além disso, através do paradigma kantiano, aderiu aos Direitos Humanos o "ponto de vista da humanidade" como operador das ações da Organização. É nesse contexto que surge o termo "temas globais" que se deu "[...] através da associação convergentes de três grandes temas: direitos humanos e democracia no plano interno e paz no plano internacional." (LAFER, 1995)

Em 26 de Junho de 1945, em São Francisco, Califórnia, foi assinada a Carta da ONU estabelecendo a organização que viria, em 1948, através da Comissão dos Direitos Humanos, a realizar a Declaração Universal dos Direitos Humanos.

\subsection{Acessibilidade}

É de grande importância definir o conceito de acessibilidade adotado nessa pesquisa, que tenta englobar o ponto de vista histórico e humano visto acima; e também aquele do meio físico.

De forma simplificada, acessibilidade seria tão somente o acesso, entretanto, acreditamos em uma acessibilidade muito mais ampla, que se relaciona fortemente com os conceitos descritos no item 3.1.. Milton Santos, geógrafo brasileiro, diz:

"Mais do que um direito à cidadania, o que está em jogo é o direito a obter da sociedade aqueles bens e serviços mínimos, sem os quais a existência não é digna. Esses bens e serviços constituem um encargo social, através das instâncias do governo, e são devido a todos. Sem isso, não se dirá que existe o cidadão. (...) $A$ acessibilidade compulsória aos bens e serviços sociais seria [deveria ser] uma parte obrigatória dos diversos projetos nacionais." (SANTOS apud MORAES, 2007). 


\section{remes $^{\text {reme }}$}

\subsection{Princípios do Desenho Universal}

"Desenho Universal quer dizer simplesmente projetar todos os produtos, prédios e espaços internos para serem usáveis para a maior extensão possível de pessoas. Foi desenvolvido como uma forma sensível e econômica de conciliar integridade artística e as necessidades humanas relacionadas aos ambientes. Soluções que não resultem em gastos adicionais $e$ em mudanças significativas na aparência podem surgir do conhecimento sobre pessoas, um planejamento simples e a seleção cuidadosa dos produtos convencionais." (MACE; HARDIE; PLACE, 1991, p.2, tradução nossa).

Em outras palavras, o Desenho Universal propõe uma arquitetura de produtos e espaços que não excluam e/ou impossibilitem pessoas com qualquer redução ou dificuldade de mobilidade, seja ela momentânea ou não, garantindo seus direitos previstos na Declaração dos Direitos Humanos.

Para tanto, Ronald Mace e um grupo de signatários (PREISER \& OSTROFF, 2001) criou, em 1987, os Sete Conceitos do Desenho Universal como parâmetros para alcançar aquilo que chamaram de "Acessibilidade Para Todos" e são eles:

- Uso equitativo e igualitário: referente ao desenvolvimento de produtos, espaços e objetos que permitam o uso por pessoas com diferentes capacidades de forma segura, que garanta a privacidade e a não segregação.

- Uso flexível: diz respeito à dimensão dos espaços, construções, a sistemas capazes de admitir transformações, adequações às necessidades e/ou preferências dos diferentes usuários.

- Uso simples e intuitivo: visa a compreensão fácil dos espaços independentemente da experiência ou das habilidades dos usuários, excluindo complexidades desnecessárias e expondo as informações em ordem de relevância.

- Informação de fácil percepção: utilização de diferentes meios e ferramentas de comunicação que atendam as necessidades de usuários com dificuldade de audição, visão, cognitivas ou estrangeiros, a fim de esclarecer as informações essenciais e tornar fácil o uso do espaço ou equipamento.

- Tolerância ao erro: refere-se, mais especificamente, a segurança através do uso de materiais e equipamentos de acabamento que minimizem os riscos de acidentes.

- Esforço físico mínimo: com a finalidade de promover o uso seguro, confortável e com mínima fadiga, diz respeito ao dimensionamento de elementos que minimizem esforços repetitivos ou inevitáveis.

- Dimensionamento de espaços para acesso e uso abrangente: considera acesso, uso confortável e alcance visual para pessoas sentadas ou em pé e a acomodação de variações ergonômicas ou de usuários com órteses.

\section{4. Legislação e Normatização}

\subsubsection{Brasil}

Dada a visibilidade de todos os acontecimentos em prol da Acessibilidade, entre as décadas de 70 e 80, em todo o mundo, o debate a respeito da mesma no Brasil impulsionou a divulgação da primeira NBR 9050 em setembro de 1985, marco da normatização a respeito da acessibilidade no país. Seguiram-se três revisões da Norma, a mais recente realizada em 2015.

O autor Miguel Corrêa de Moraes, em sua dissertação de mestrado, "Acessibilidade no Brasil: Análise da NBR 9050" descreve detalhadamente as três primeiras versões da Norma, 


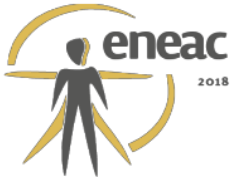

atentando-se principalmente aos conceitos de Acessibilidade, Desenho Universal e Deficiência que cada uma trazia.

A NBR 9050/85 intitulada por "adequação das edificações e mobiliário urbano à pessoa deficiente" foi elaborada pelo Comitê Brasileiro de Construção Civil, CB-2, com o objetivo principal de fixar medidas que proporcionassem às pessoas com deficiência o acesso a edifícios e vias públicas (MORAES, 2007).

"Acessibilidade de pessoas portadoras de deficiência a edificações, espaços, mobiliários e equipamentos urbanos" foi o título dado à versão de outubro de 1994, que já demonstrava mudanças especialmente com relação aos conceitos de Acessibilidade, agora inserido na Norma; Desenho Universal; e uma nova abordagem a respeito da "pessoa portadora de deficiência." (MORAES, 2007).

A última versão da NBR 9050 trazida por Moraes (2007), datada de maio de 2004, possuía o título "Acessibilidade a edificações, mobiliários, espaços e equipamentos urbanos" que já anunciava uma assimilação mais profunda dos conceitos adquiridos na versão anterior e tinha por objetivo:

“(...) proporcionar à maior quantidade possível de pessoas, independentemente de idade, estatura ou limitação de mobilidade ou percepção, a utilização de maneira autônoma e segura do ambiente, edificações, mobiliário, equipamentos urbanos e elementos." (ABNT, 2004).

O autor utiliza-se do momento histórico em que foram promulgadas cada uma das versões e compara-os aos conceitos explicitados nas mesmas. Conclui que as principais contradições estão no conceito de Acessibilidade da NBR 9050/94, cujo título traz "acessibilidade de pessoas portadoras de deficiências..." contraditório ao conceito em si e também a falta dos termos como conforto, orientação e comunicação; e no conceito de Deficiência e restrição na Norma de 2004, que ainda atribui a limitação exclusivamente à deficiência e não ao ambiente apesar da já existência do conceito da Classificação Internacional de Funcionalidades, Incapacidade e Saúde - ICF (CBCD apud Moraes, 2007).

Segundo Guimarães (2008) "tudo isso serve de base para reflexões sobre uma nova definição do público-alvo beneficiário do design universal. Com o Decreto Federal 5296/2004 e com a NBR 9050/2004, pela primeira vez contemplamos ideias que sirvam não apenas para as pessoas agrupadas em rótulos de categorias de deficiência, mas para as pessoas que tenham sua mobilidade reduzida, tais como mulheres grávidas, idosos e acidentados. (...) A noção de deficiência desvinculada do problema geral de mobilidade reflete a noção de estereótipo. Quando começarmos a olhar esses problemas de maneira global, sem querer caracterizá-los isoladamente e vendo um em relação direta com os outros, estaremos contemplando como o design universal pode ser praticado."

Para ambos os autores a terminologia referente à deficiência, e sua alteração ao longo do tempo, representa parte importantíssima da questão geral da promoção de acessibilidade. No Brasil esse tema foi fortemente marcada pelo Decreto Executivo de 02 de Dezembro de 2004, que regulamenta as Leis $\mathrm{N} .-10.048$, de 8 de novembro de 2000, e 10.098, de 19 de dezembro de 2000 (BRASIL, 2004); e pelo Parecer nำ21/2009/CONADE/SEDH/PR que diz:

“(...) a Convenção sobre os Direitos das Pessoas com Deficiência da ONU consagra o termo 'pessoas com deficiência' no ordenamento jurídico brasileiro e, portanto, constitui a linguagem mais apropriada para se referir às pessoas com deficiência(...)." (BRASIL, 2009; COSTA ,2013).

\subsubsection{Estados Unidos}

A lei norte americana American with Disability Act (ADA) é, para muitos autores, referência global na questão da acessibilidade. Estruturada em tópicos que abordam as diferentes 


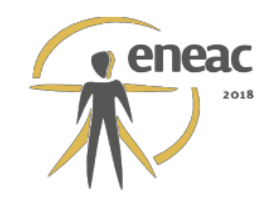

áreas da vida pública, a lei visa garantir que pessoas com deficiência sejam contempladas com os mesmos direitos e oportunidades que as demais (U.S, DEPARTMENT OF JUSTICE CIVIL RIGHTS DIVISION, 2008).

Souza (2012) em sua pesquisa sobre a adaptação de casas para pessoas com deficiência adquirida, compara as diferentes formatações entre a lei brasileira e a norte americana relativa ao assunto, sendo essa última quase toda concentrada em documento único promulgado como lei federal. Os cinco principais tópicos da ADA trazem consigo os seguintes escopos:

I) Emprego: ajuda pessoas com deficiência a acessar as mesmas oportunidades de trabalho e benefícios que pessoas sem deficiência. Aplica-se ao empregador com mais de 15 funcionários, requer do mesmo fornecer "acomodação razoável" para candidatos elou funcionários qualificados, define deficiência e dá diretrizes sobre o processo de "acomodação razoável", exames e consultas médicas;

II) Serviços Públicos: proíbe a discriminação por parte das entidades públicas em todos os seus níveis, requer das mesmas tornar seus programas, serviços e atividades acessíveis às pessoas com deficiência. Concebe requisitos para a auto avaliação, planejamento, modificação razoável das leis para não discriminar, identificação de barreiras arquitetônicas e comunicação efetiva com deficientes auditivos, de visão e de fala;

III) Espaços públicos e serviços particulares: proíbe que esses locais discriminem indivíduos com deficiência. Define que as "acomodações públicas" incluem instalações privadas arrendadas ou operadas por elas, e estabelece padrões mínimos de acessibilidade para alterações e novas construções de instalações comerciais e acomodações públicas. Requer das mesmas, medidas necessárias para a comunicação efetiva com clientes com dificuldades de visão, audição e fala, bem como a remoção de barreiras em prédios. Direciona as empresas a "modificação razoável" de sua forma de fazer as coisas ao atender pessoas com deficiência;

IV) Telecomunicações: requer de empresas de telefonia e internet o fornecimento de um serviço nacional de telecomunicações interestaduais e intraestaduais que permita às pessoas com deficiência auditiva ou de fala se comunicar por telefone, bem como subtítulos fechados nos anúncios do serviço público financiados pelo governo federal; e

V) Provisões diversas: Contém uma variedade de disposições relativas à ADA como um todo, incluindo sua relação com outras leis, imunidade estadual, seu impacto em provedores de seguros e benefícios, proibição contra retaliação e coação, uso ilegal de drogas e honorários advocatícios. Fornece uma lista de certas condições que não são consideradas deficiências.

Cada um desses títulos traz considerações próprias para cada região do país, uma vez que, nos Estados Unidos os estados são muito mais autônomos e, portanto, podem possuir leis próprias sobre determinadas coisas, desde que em acordo com a legislação estipulada em nível nacional. Isso faz com que a implementação dessa legislação seja diferente da brasileira.

A Figura 1 exibe essa repartição por regiões.

Figura 1: Mapa das Regiões ADA 


\section{ieneac}

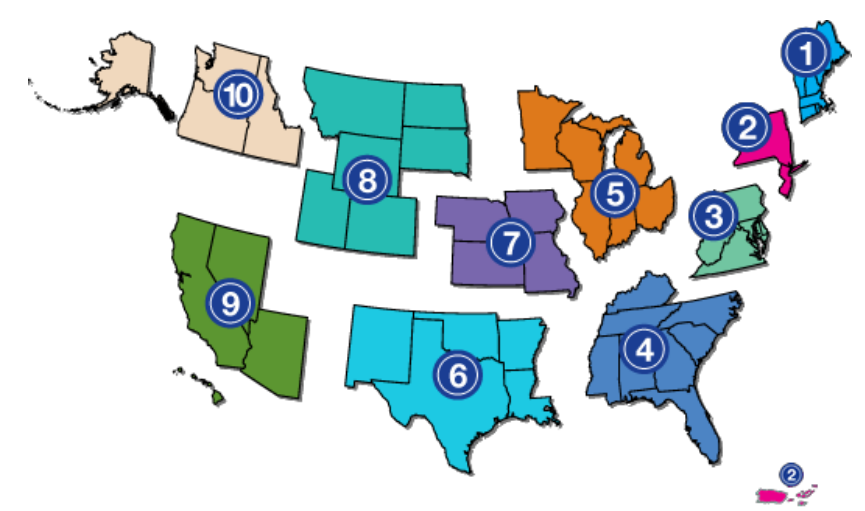

Fonte: ADA Center. Disponível em: <https://adata.org/find-your-region\#region10>. Acesso em nov/2017.

De acordo com o site da ADA National Network, cada região componente do mapa corresponde a: Region 1 - New England ADA Center; Region 2 - Northeast ADA Center; Region 3 - Mid-Atlantic ADA Center; Region 4 - Southeast ADA Center; Region 5 - Great Lakes ADA Center; Region 6 - Southwest ADA Center at ILRU; Region 7 - Great Plains ADA Center; Region 8 - Rocky Mountain ADA Center; Region 9 - Pacific ADA Center; e Region 10 - Northwest ADA Center. É importante ressaltar que nem todas as regiões ou estados têm legislação específica para cada título do documento, seguindo apenas as recomendações federais.

A $A D A$, em seu início, indica a necessidade da existência das determinações que outorga e possui preâmbulo que explicita o propósito dessa legislação. Nela a deficiência é trazida como "condição limitante" (SOUZA, 2012).

A ADA Standards apresenta critérios e parâmetros técnicos para a promoção de acessibilidade a edifícios, que não expõe os padrões antropométricos adotados, apenas cita que foram utilizadas medidas de adulto, mas aborda com especificidade cada tipo de edifício, ambiente e atividade realizada. É um documento que trata menos dos critérios de sinalização e comunicação do que os documentos brasileiros, contudo, sua estruturação demonstra, na prática, que a acessibilidade é pensada como um todo partindo das áreas externas e novas construções até os requisitos especiais por tipo de uso, como restaurantes, por exemplo. Isso dá a ela um caráter educativo para o projetista, que vai acessar e internalizar as informações com mais simplicidade, e ser capaz de desenvolver um projeto pensado para ser acessível e não adaptado aos requisitos (SOUZA, 2012).

\section{DESENVOLVIMENTO}

O desenvolvimento deste trabalho foi embasado em todo o levantamento bibliográfico realizado, a partir do qual foram elencados os principais conceitos históricos e apontamentos feitos pelos autores referentes à acessibilidade e ao Universal Design; e também reunida à legislação nacional e e norte americana.

A análise da legislação brasileira foi feita com base em 6 categorias de acessibilidade descritas por Romeu Sassaki (2004) e organizadas em uma Tabela de Categorização. São as categorias:

- Arquitetônica: acessibilidade alcançada pela eliminação das barreiras físicas dos espaços;

- Atitudinal: relacionada a atitudes que não sejam preconceituosas nem discriminatórias; 


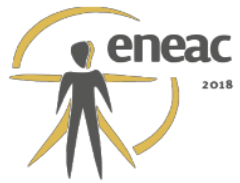

- Comunicacional: quando a linguagem verbal, visual e virtual alcança todos na comunicação face-a-face, textual ou de linguagem corporal;

- Instrumental: diz respeito aos instrumentos de estudo, trabalho ou qualquer outra atividade rotineira que são projetados ou adequados ao uso por pessoas que possuem dificuldades ou redução de mobilidade, de forma independente e igual;

- Metodológica: acessibilidade alcançada quando os métodos e técnicas de trabalho, estudo e ação comunitária são homogêneos e atendem as diferentes limitações;

- Pragmática: promovida nas leis, normas, portarias e ou políticas públicas que garantem os direitos das pessoas com deficiência enquanto ser dotado de direitos.

A análise da legislação norte americana, também foi feita tendo por base as características de acessibilidade descritas por Sassaki, entretanto, a legislação ADA difere da brasileira, como visto no tópico 2.4. deste trabalho. Assim, foi necessário submeter cada título da $A D A$ às características defendidas por Sassaki, a fim de organizá-la nas mesmas categorias utilizadas com a legislação nacional e tornar possível a discussão sobre ambas.

O resultado dessa análise encontra-se na Tabela 1:

Tabela 1: Tabela de Categorização

\begin{tabular}{|c|c|c|c|c|c|c|c|}
\hline $\begin{array}{l}\text { Tipo de } \\
\text { acessibilidade }\end{array}$ & País & Ano & $\begin{array}{l}\text { Tipo de } \\
\text { aplicação }\end{array}$ & Escopo & $\begin{array}{l}\text { Validação da } \\
\text { lei: } \\
\text { BRA: Decreto } \\
\text { EUA: Regiões } \\
\end{array}$ & Ano & Escopo \\
\hline \multirow[t]{2}{*}{ Arquitetônica } & BR & $\begin{array}{l}20 \\
00\end{array}$ & Lei $n^{0} 10.098$ & $\begin{array}{l}\text { Normas } \\
\text { gerais } \\
\text { critérios } \\
\text { básicos } \\
\end{array}$ & $\begin{array}{l}\text { Decreto } \\
5.296\end{array}$ & $\begin{array}{l}20 \\
04\end{array}$ & $\begin{array}{l}\text { Regulament } \\
\text { a a Lei no } \\
10.098\end{array}$ \\
\hline & US & $\begin{array}{l}20 \\
08\end{array}$ & $\begin{array}{l}\text { Título II da Lei } \\
\text { ADA }\end{array}$ & $\begin{array}{l}\text { Transportes } \\
\text { públicos }\end{array}$ & $\begin{array}{l}\text { Regiões } 1,3,5 \\
7,8,9 \text { e } 10\end{array}$ & $\begin{array}{l}20 \\
08\end{array}$ & $\begin{array}{l}\text { Estudos de } \\
\text { caso }\end{array}$ \\
\hline \multirow[b]{2}{*}{ Atitudinal } & BR & $\begin{array}{l}20 \\
00\end{array}$ & Lei $n^{\circ} 10.048$ & \begin{tabular}{|l|} 
Prioridade \\
de \\
atendimento
\end{tabular} & $\begin{array}{l}\text { Decreto } \quad \mathrm{n}- \\
5.296\end{array}$ & $\begin{array}{l}20 \\
04\end{array}$ & $\begin{array}{l}\text { Regulament } \\
\text { a a Lei no } \\
10.048\end{array}$ \\
\hline & US & $\begin{array}{l}20 \\
08\end{array}$ & $\begin{array}{l}\text { Título III da } \\
\text { Lei ADA. }\end{array}$ & $\begin{array}{l}\text { Ambientes } \\
\text { públicos } \\
\text { facilidades } \\
\text { comerciais }\end{array}$ & $\begin{array}{l}\text { Regiões 3, 4, } 9 \\
\text { e } 10 .\end{array}$ & $\begin{array}{l}20 \\
08\end{array}$ & $\begin{array}{l}\text { Estudos de } \\
\text { caso }\end{array}$ \\
\hline \multirow{2}{*}{$\begin{array}{l}\text { Comunicaciona } \\
\text { I }\end{array}$} & BR & $\begin{array}{l}20 \\
02\end{array}$ & Lei $n^{0} 10.436$ & Libras & $\begin{array}{l}\text { Decreto } \\
5.626\end{array}$ & $\begin{array}{l}20 \\
05\end{array}$ & $\begin{array}{l}\text { Regulament } \\
a \quad \text { Lei } \quad \text { no } \\
10.436\end{array}$ \\
\hline & US & $\begin{array}{l}20 \\
08\end{array}$ & $\begin{array}{l}\text { Título IV da } \\
\text { Lei ADA. }\end{array}$ & $\begin{array}{l}\text { Telecomunic } \\
\text { a } \\
\text { ções }\end{array}$ & - & - & - \\
\hline Instrumental & BR & \multicolumn{6}{|c|}{ Não foi encontrada legislação correspondente } \\
\hline
\end{tabular}




\section{策}

\begin{tabular}{|c|c|c|c|c|c|c|c|}
\hline & US & $\begin{array}{l}20 \\
08\end{array}$ & $\begin{array}{ll}\text { Título III } \\
\text { da } & \text { Lei } \\
\text { ADA. } & \end{array}$ & $\begin{array}{l}\text { Ambientes } \\
\text { públicos } \\
\text { facilidades } \\
\text { comerciais. }\end{array}$ & $\begin{array}{l}\text { Regiões 3, 4, } 9 \\
\text { e } 10 .\end{array}$ & $\begin{array}{l}20 \\
08\end{array}$ & $\begin{array}{l}\text { Estudos de } \\
\text { caso }\end{array}$ \\
\hline \multirow{2}{*}{ Metodológica } & BR & $\begin{array}{l}20 \\
04\end{array}$ & $\begin{array}{l}\text { Lei }{ }^{\circ}{ }^{\circ} \\
10.845\end{array}$ & $\begin{array}{l}\text { Atendimento } \\
\text { educacional } \\
\text { especializado }\end{array}$ & - & - & - \\
\hline & US & $\begin{array}{l}20 \\
08\end{array}$ & $\begin{array}{l}\text { Título I da } \\
\text { Lei ADA }\end{array}$ & $\begin{array}{l}\text { Empregabilidad } \\
\mathrm{e}\end{array}$ & $\begin{array}{l}\text { Regiões } 1,2,3 \\
4,5,6,7,8 \text { e } 10\end{array}$ & $\begin{array}{l}20 \\
08\end{array}$ & $\begin{array}{l}\text { Estudos de } \\
\text { caso }\end{array}$ \\
\hline \multirow[b]{2}{*}{ Pragmática } & $\mathrm{BR}$ & $\begin{array}{l}20 \\
12\end{array}$ & $\begin{array}{l}\text { Lei }{ }^{\circ}{ }^{\circ} \\
12.764\end{array}$ & $\begin{array}{lr}\text { Direitos } & \text { da } \\
\text { pessoa } & \text { com } \\
\text { transtorno } & \text { do } \\
\text { espectro autista }\end{array}$ & $\begin{array}{l}\text { Decreto } \\
8.368\end{array}$ & $\begin{array}{l}20 \\
14\end{array}$ & $\begin{array}{l}\text { Regulament } \\
\text { a a Lei no } \\
12.764\end{array}$ \\
\hline & US & $\begin{array}{l}20 \\
08\end{array}$ & $\begin{array}{lr}\text { Título } & \text { V } \\
\text { da } & \text { Lei } \\
\text { ADA. } & \end{array}$ & $\begin{array}{l}\text { Provisões } \\
\text { diversas e lista } \\
\text { condições não } \\
\text { consideradas } \\
\text { como } \\
\text { deficiência. }\end{array}$ & - & - & - \\
\hline
\end{tabular}

Fonte: elaborado pelos autores.

\section{RESULTADOS}

Com base nesta categorização, os resultados apontam uma grande concentração dos esforços da legislação brasileira na Acessibilidade Pragmática garantindo, assim, uma acessibilidade jurídica. Isso justifica a percepção dos autores sobre um grande volume de leis relativas ao tema. Contudo, essa garantia ainda não alcança efetividade na promoção da acessibilidade.

Em sequência, a Acessibilidade Comunicacional também recebe destaque em leis e decretos que dão diretrizes sobre o uso de Libras, de Braille, intérpretes ou tecnologias que promovam a comunicação oral, textual ou gestual. Essa se faz demasiadamente importante na garantia dos direitos da pessoa com deficiência, uma vez que o direito de comunicar-se e, através disso, interagir com o ambiente e com pessoas em seu entorno, estabelecendo núcleos de convivência é a garantia da construção de uma sociedade saudável e inclusiva.

As categorias Arquitetônica e Atitudinal são as que menos aparecem na legislação nacional, demonstrando uma lacuna na promoção da acessibilidade física a espaços públicos ou privados por pessoas com deficiência elou mobilidade reduzida, bem como a persistência da cultura de preconceito e discriminação, gerando consequente desrespeito aos seus direitos.

A Acessibilidade Instrumental não teve nenhuma representação na legislação levantada, o que atesta o fato de nossos equipamentos e ferramentas utilizados em atividades rotineiras não serem pensados ou projetados para o uso por pessoas com diferentes níveis de mobilidade, negando a elas o uso autônomo e igual, excluindo-as muitas vezes das atividades educacionais ou de trabalho. 


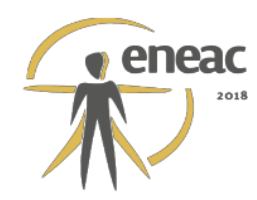

Acessibilidade Metodológica é retratada principalmente em 3 leis e um decreto nacional. Esta legislação aborda a questão educacional, de atendimento especial, de intérprete de Libras. São questões relacionadas à assistência social continuada.

Os resultados referentes às leis norte americanas apontam que os títulos I, II e III são os que mais apresentam diretrizes para a promoção da acessibilidade e não só em uma das categorias. Todas as seis categorias têm representação em pelo menos um desses, com exceção da categoria Pragmática que, apesar de aparecer em cada um dos títulos, por exemplo, com a "não discriminação" elou "definição de crimes", está majoritariamente concentrada no título $\mathrm{V}$, que dá provisões diversas a respeito dos direitos da pessoa com deficiência.

A Acessibilidade Comunicacional e a Metodológica foram as mais evidenciadas, aparecendo em três dos cinco títulos da $A D A$. Observa-se, na abordagem de questões como a adoção de medidas para comunicação efetiva com pessoas com deficiência na prestação de serviços, públicos ou privados, e na universalização dos serviços de telecomunicações, o esforço para que a comunicação seja garantida. Assim como, os requisitos para tornar acessível a essas pessoas os ambientes de trabalho, seus processos de planejamento, auto avaliação e até mesmo a "modificação razoável", por parte das instituições, de sua forma de fazer as coisas para melhor atender as pessoas com deficiência, mostram similar esforço para incluí-las e atendê-las nas atividades cotidianas.

As categorias Arquitetônica, Atitudinal e Instrumental, todas representadas em três títulos, também reforçam a atenção dada ao ambiente acessível, tanto física quanto socialmente, por parte da eliminação de barreiras arquitetônicas e de discriminação, tanto por parte das pessoas como de instrumentos não adequados ao uso.

A Acessibilidade Pragmática, como dito anteriormente, concentra-se em um único título, contudo isso não indica, na ADA, uma falta de respaldo jurídico, tendo em vista que cada título, ao tratar dos temas de empregabilidade, acesso a serviços e lugares, por exemplo, traz inicialmente determinações gerais sobre 0 direito da pessoas com deficiência relacionada aquele tema e também proíbe a discriminação e outros.

\section{CONSIDERAÇÕES FINAIS}

Muitos autores observam que a legislação brasileira, embora vasta, carece de maiores especificações principalmente de cunho teórico e conceitual, deixando espaço a ser preenchido pela interpretação e criatividade dos profissionais da área, enquanto isso a acessibilidade no país não têm sido alcançada nas proporções que poderia e deveria.

Houve, entre 2004 e 2015, a promulgação de diversos trabalhos abordando a Norma NBR $9050 / 2004$, contudo, por ser muito recente, considera-se ainda precoce a publicação e divulgação de artigos, com resultados validados, de pesquisas que abordam especificamente o caso da revisão da NBR 9050 de 2015 que poderiam ser citados como referência no que diz respeito ao impacto na aplicação de diretrizes e ações projetuais e de políticas públicas. Espera-se, nos próximos anos, que estudos sobre a revisão desta versão da Norma sejam realizados, que analisem seus impactos sobre a acessibilidade e no Brasil e como de fato a legislação nacional conduzirá a promoção de acesso e inclusão para todas as pessoas.

A pesquisa permitiu compreender as diferenças estruturais e de abordagem de cada legislação, a fim de promover uma discussão equiparada entre as duas e identificar as características que as categoriza como promotoras de um ou outro tipo de acessibilidade e sua efetividade.

Diferentemente do documento norte americano, a norma brasileira sobre edificações não apresenta caráter educativo, ou seja, não leva os projetistas à concepção e construção de 


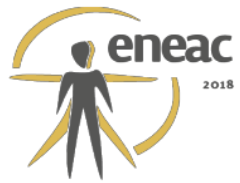

ambientes, métodos e instrumentos que sejam originalmente acessíveis. Atua como um manual técnico para adaptação do projeto sem discutir muito a importância e impacto que a garantia de acesso tem para toda a sociedade (SOUZA, 2012). Isso pode ter contribuição da falta aprofundamento sobre o que seria o Desenho Universal nos instrumentos legais e normativos do Brasil (GUIMARÃES, 2009).

Há considerável volume de leis, decretos e normas relacionados ao tema no Brasil no âmbito federal e que são majoritariamente voltadas às questões jurídicas e pouco voltadas para o cotidiano urbano das pessoas com deficiência. A falta de determinações que considerem as especificidades de cada região, como o faz a legislação $A D A$, pode gerar maiores dificuldades na aplicação das medidas para a acessibilidade.

A falta de fiscalização, somada a cultura de não valorização da pessoa com deficiência, é outro fator que desempenha importante papel para o não cumprimento das diretrizes sobre acessibilidade.

Por esses motivos e com respaldo nas observações de diversos autores a respeito das leis brasileiras, considera-se a legislação brasileira, apesar de vasta, carente de determinações efetivas em prol da acessibilidade universal, principalmente no tocante a acessibilidade arquitetônica.

Torna-se necessário, no Brasil, o desenvolvimento de maiores especificações aos profissionais das áreas envolvidas com a acessibilidade, bem como políticas públicas que promovam o conhecimento dos direitos de que são dotadas as pessoas com deficiência, dos deveres que o Estado e a sociedade têm para com a garantia dos direitos iguais a todos e, por último, medidas que tragam à sociedade a consciência da não discriminação e do valor social que tem a pessoa com deficiência. Espera-se que com isso haja movimentações em direção a mudanças que vão significar de fato uma sociedade acessível e inclusiva.

Essa pesquisa deixa para trabalhos futuros um panorama sobre os esforços da legislação nacional e norte americana, baseado na categorização de Sassaki (2004), que explicita algumas lacunas que as mesmas possuem, sendo recomendado que, a partir disso, se realize estudos que acompanhem a implementação de medidas previstas em lei nos níveis regionais, estaduais elou municipais e que sejam capazes de medir qualitativamente a efetividade de tais ações nesse mesmo âmbito e, ainda, analisar a compatibilidade entre as diretrizes e seu local de efetivação.

\section{REFERÊNCIAS BIBLIOGRÁFICAS}

ABNT - Associação Brasileira de Normas Técnicas. NBR9050: Acessibilidade às edificações, mobiliário, espaços e equipamentos urbanos. 3a ed. Rio de Janeiro, 2015.

ABNT - Associação Brasileira de Normas Técnicas. NBR9050: Acessibilidade às edificações, mobiliário, espaços e equipamentos urbanos. 2a ed. Rio de Janeiro, 2004.

ADAPTIVE ENVIRONMENT CENTER. History of Universal Design. Institut for Human Centered Design. Disponível em

http://www.adaptiveenvironments.org/index.php?options=Content\&ltemid=26. Acesso em novembro de 2017.

BRASIL. Decreto no 5296 de 2 de dezembro de 2004. Portal da Legislação .Disponível em: <http://www.planalto.gov.br/ccivil_03/_ato2004-2006/2004/decreto/d5296.htm> Acesso em 05/05/2017.

BRASIL. Secretaria Nacional de Promoção dos Direitos da Pessoa com Deficiência. Parecer no 21/2009/CONADE/SDHE/PR. Disponível em:

<http://www.pessoacomdeficiencia.gov.br/app/legislacao> Acesso em 05/05/2017. 


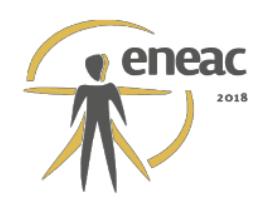

COSTA, Mariela Cristina Aguiar. A percepção dos professores sobre a qualificação profissional para pessoas com deficiência intelectual. Dissertação (Mestrado), Universidade Federal de São João Del Rei, 2013.

CENTRO BRASILEIRO DE CLASSIFICAÇÃO DE DOENÇAS (CBCD). CIF: Classificação Internacional de Funcionalidade, Incapacidade e Saúde. [200-]. Disponível em: http://hygeia.fsp.usp.br/ cbcd/cifWeb.htm in MORAES. M. C. de. Acessibilidade no Brasil: análise da NBR 9050. Dissertação (Mestrado) Florianópolis: UFSC, Faculdade de Arquitetura e Urbanismo, Programa de Pós-Graduação em Arquitetura e Urbanismo, 2007.

COMPARATO. F. K. A afirmação histórica dos Direitos Humanos. 7a ed. revista e atualizada. Editora Saraiva, 2010.

CONADE- Conselho Nacional da Pessoa com Deficiência. Parecer no21/2009/CONADE/SEDH/PR. Disponível em: <http://www.mpgo.mp.br/portalweb/hp/41/docs/parecer__mudanca_da_nomeclatura.pdf> Acesso em 06/07/2017.

GUIMARÃES. M. P. Uma abordagem holística na prática do design universal. In: Avanços e desafios na construção de uma sociedade inclusiva. Belo Horizonte : Sociedade Inclusiva/PUCMG, 2008. p. 88.

KULPA. C. C; TEIXEIRA F. G; SILVA. R. P. Um Modelo de Cores na Usabilidade das Interfaces Computacionais para os Deficientes de Baixa Visão. Porto Alegre, Brasil: Universidade Federal do Rio Grande do Sul, 2010.

LAFER, C. A ONU e os direitos humanos. Estud. av., São Paulo, v. 9, n. 25, Dec. 1995. Disponível em: <http://www.scielo.br/scielo.php?pid=S0103-40141995000300014\&script=sci_arttext> Acesso em $15 / 04 / 2017$.

MACE. R. L; HARDIE. G. J; PLACE. J. P. Accessible Environments: toward the Universal Design. New York, USA: North Carolina State University, 1991.

MORAES. M. C. de. Acessibilidade no Brasil: análise da NBR 9050. Dissertação (Mestrado) Florianópolis: UFSC, Faculdade de Arquitetura e Urbanismo, Programa de Pós-Graduação em Arquitetura e Urbanismo, 2007.

PREISER, W. F. E.; OSTROFF, E (ed).Universal Design Handbook. New York: Mc-Graw-Hill, 2001.

SANTOS, Milton. Metamorfoses do espaço habitado. São Paulo, Hucitec, 1988. In MORAES. M. C. de. Acessibilidade no Brasil: análise da NBR 9050. Dissertação (Mestrado). Florianópolis: UFSC, Faculdade de Arquitetura e Urbanismo, Programa de Pós-Graduação em Arquitetura e Urbanismo, 2007.

SASSAKI. R. Revista do Terceiro Setor, 04 de junho de 2004. Disponível em http://arruda.rits.org.br. Acesso em: jan. 2005.

SOUZA. L. R. de. A casa acessível: o projeto de reforma residencial para pessoas com deficiência adquirida. Dissertação (Mestrados)Campinas: UNICAMP, Faculdade de Engenharia Civil, Arquitetura e Urbanismo, Programa de Pós-Graduação em Engenharia Civil, 2012.

U.S. DEPARTMENT OF JUSTICE CIVIL RIGHTS DIVISION. Americans with disabilities act of 1990 - title I, title II, title III, title IV and title V, revisão 2008. Disponível em:

<http://www.ada.gov/pubs/ada.htm>. Acesso em: 04 out. 2017. 